\title{
Early variations in augmentation index and pulsed wave velocity in patients with obstructive sleep apnea and arterial hypertension post CPAP treatment
}

\begin{abstract}
Background:Obstructive sleep apnea (OSA) is a risk factor for hypertension and if left untreated, is associated with high cardiovascular morbidity and mortality. Continuous positive airway pressure (CPAP) is considered the therapy of choice for moderate and severe OSA. (CPAP) reduces peripheral blood pressure and arterial stiffness. Arterial stiffness is measurable and evaluated by pulse wave velocity (PWV) and augmentation index as early markers of atherosclerosis and cardiovascular (CV) risk. The aim of this study was to assess the early effects of (CPAP) on augmentation index and pulsed wave velocity of arterial stiffness in patients with (OSA) and arterial hypertension.
\end{abstract}

Patients and Methods: The study conducted at Zagazig Cardiology and Chest Departments. Sixty patients divided into two groups: each group was thirty patients, the first group: moderate OSA with hypertension, the second group: severe OSA with hypertension. Inclusion criteria: Patients referred to the Sleep Clinic of the Chest Department, because of snoring or sleepiness with confirmed moderate-to-severe OSA (apnea/hypopnea index $>15 / \mathrm{h}$ and $>30 / \mathrm{h}$ ) and known to have hypertension on continuous antihypertensive treatment with BP less than 140/90mmHg. Exclusion criteria: Patients with severe chronic diseases, peripheral vascular disease, and diabetes. Sleep study was done to confirm the diagnosis of OSA. Ambulatory blood pressure monitoring was done to confirm the diagnosis of hypertension. Non-invasive assessment of central aortic pressure and measuring pulse wave velocity and augmentation index .Standard CPAP intervention was done. Follow-up was done after 12 weeks of standard CPAP intervention.

Results: The effective CPAP treatment after 12weeks showed significant BP reduction, in central systolic BP $(6.2 \pm 1.6 \mathrm{mmHg}, P<0.005)$, diastolic $\mathrm{BP}(4.4 \pm 0.7 \mathrm{mmHg}, P<0.001)$ and, brachial systolic $\mathrm{BP}(5.4 \pm 1.4 \mathrm{mmHg}, P<0.03)$ and diastolic $\mathrm{BP}(4.2 \pm 0.8 \mathrm{mmHg}, P<$ $0.05)$ and achieved $P W V$ reduction by $1.7 \pm 1.2 \mathrm{~m} / \mathrm{sec}(P<0.005)$ and a significant reduction in augmentation index (the augmentation index was $24.8 \% \pm 11.9 \%$ ) and the significant reduction in augmentation index up to $6.1 \%(P<0.05)$.

Conclusion: The effective CPAP therapy reduces both central aortic and peripheral blood pressure and improvements in arterial stiffness parameters. The effective reduction of augmentation index and arterial stiffness will prevent cardiovascular morbidity and mortality.

Keywords: hypertension, obstructive sleep apnea, continuous positive airway pressure, pulse wave velocity, augmentation index, arterial stiffness
Volume 9 Issue 2 - 2017

\author{
Wael A Khalil,' Ahmad Eldamanhory,' \\ Waleed Mansour, ${ }^{2}$ Marwa B Awad Allah ${ }^{3}$ \\ 'Lecturer of Cardiology, Faculty of Medicine, Zagazig University, \\ Egypt \\ 2Lecturer of Chest Disease, Faculty of Medicine, Zagazig \\ University, Egypt \\ ${ }^{3}$ Lecturer of Public Health, Faculty of Medicine?Zagazig \\ University, Egypt
}

\begin{abstract}
Correspondence: Wael A Khalil, Lecturer of Cardiology, Faculty of Medicine, Zagazig University, Egypt, Tel 201015560968,
\end{abstract} Email drwael 123456@yahoo.com

Received: May II, 2017 | Published: June 19, 2017

\section{Introduction}

Obstructive sleep apnea (OSA) is a chronic repeated upperairway obstruction during sleep, characterized by repetitive apnea, hyperpnoea and oxygen desaturations leading to interrupted sleep, variations in blood pressure, and increased sympathetic nervous system activity. ${ }^{1}$ The prevalence of OSA is $2-4 \%$ in the general population. $^{2-4}$ The prevalence of cardiovascular disease (systemic hypertension, coronary artery disease and cerebrovascular disease) was high in OSA patients. ${ }^{5}$ The number of OSA patients with hypertension is high (35\%) to $(70 \%)^{6,7}$ and nearly $30 \%$ of patients presenting with hypertension also have OSA. ${ }^{8}$ OSA has been proven to be a causal factor in the pathogenesis of vascular dysfunction and hypertension. ${ }^{9}$ The Noninvasive assessment of arterial stiffness by the measurement of pulsed wave velocity (PWV) and augmentation index is a predictor of cardiovascular morbidity and mortality in hypertensive patients. ${ }^{10}$ The Continuous positive airway pressure
(CPAP), is considered the first line treatment for OSA and can decrease the arterial stiffness in hypertensive patients with obstructive sleep apnea. ${ }^{11,12}$

The aim of this study was to assess the early effects of (CPAP) on augmentation index and pulsed wave velocity of arterial stiffness in patients with (OSA) and arterial hypertension.

\section{Patients and methods}

The study was conducted at Zagazig Cardiology and Chest Departments from December 2015 to December 2016.

A. Inclusion criteria: Patients referred to the Sleep Clinic at the Chest Department, because of snoring or sleepiness with confirmed moderate-to-severe OSA (apnea/hypopnea index $>15 / \mathrm{h}$ and $>30 / \mathrm{h}$ ) and known to have hypertension on continuous antihypertensive treatment with BP less than $140 / 90 \mathrm{mmHg}$. 
B. Exclusion criteria: Patients with severe chronic diseases, eg liver cirrhosis, cardiomyopathy, renal failure and peripheral vascular diseases. Sixty patients were enrolled in this study and divided into two groups; each group was 30 patients, the first group: moderate OSA with hypertension, the second group: severe OSA with hypertension.

\section{Study protocol}

Polysomnography \& CPAP treatment: Polysomnography was done to confirm the diagnosis of OSA. All patients underwent overnight polysomnography using a standard technique. Polysomnography was done (SOMNOscreen plus 4447, Germany). The system consists of 4 channels of electroencephalography, 2 channels of electrooculography, submental electromyography, oronasal airflow, thoracic and abdominal movements, pulse oximeter oxygen saturation, tibial EMG, body position detector, electrocardiogram and tracheal sound. Sleep stages were scored. ${ }^{13}$ Apnea was defined as complete stopping of airflow lasting more than 10seconds. Hypopnea was defined as $30 \%$ or more reduction in respiratory airflow lasting $\geq 10$ seconds which is accompanied by a decrease of $\geq 4 \%$ in oxygen saturation or arousal in EEG. Apnea-hypopnea index (AHI) was defined as the number of apneas and hypopneas per hour. OSAS was defined as apneas or hypopneas $\geq 5 \mathrm{AHI}$ events per hour in the presence of clinical symptoms suggesting OSAS. ${ }^{14,15}$ According to the severity, included patients were classified as mild OSA (AHI between 5 and 15), moderate OSA (AHI between 15 and 30) and severe OSA $(\mathrm{AHI} \geq 30){ }^{16,17}$ The patients with OSA underwent auto CPAP titration (Weinmann, prisma 20A auto CPAP, Germany) and the target CPAP pressure was $\mathrm{P} 95$ recoeded by the device. Effective OSA therapy was defined as $>25 \%$ drop in AHI of CPAP treatment and mean reduction in Epworth Sleepiness Score of 3 points. ${ }^{18,19}$

Blood pressure measurement: Ambulatory blood pressure monitoring was done to confirm the diagnosis of hypertension. Arterial hypertension was diagnosed according to current guidelines published by the European Society of Hypertension. ${ }^{20}$ BP measurements were determined using a conventional mercury sphygmomanometer. ${ }^{21}$ Non-invasive assessment of central aortic pressure and measuring pulse wave velocity and augmentation index. The brachial pulse wave velocity (PWV), central BP, and systolic wave augmentation index were measured using a mobil-o-graph 24h PWA monitor (IEM, Stolberg, Germany using single oscillometric measurement of the brachial BP by simultaneously obtaining the pulse wave contour. ${ }^{22,23}$ The new oscillometric device mobil-o-graph 24h PWA monitor (IEM, Stolberg, Germany) with appropriately sized arm cuffs. After obtaining brachial BP, the cuff was again inflated, maintaining the diastolic pressure level for $10 \mathrm{~s}$ for assessment of the pulse waveform. ${ }^{6}$ Each measurement cycle with the mobil-o-graph. ${ }^{24}$ By inflating the cuff after conventional BP measurement to the diastolic BP level, the brachial arterial pressure waveform can be determined with a high-fidelity pressure sensor. Using generalized transfer functions, the aortic pressure waveform can be generated from the obtained brachial artery pulse waveform. The measurement was in the supine position after 15 minutes rest by PWA of the brachial artery waveform using mobil-o-graph 24h PWA monitor (IEM, Stolberg, Germany). Augmentation index were both corrected for a heart rate of 75 beats per minute (AIx75) using an automatic calculation determined by the PWA software. The augmentation index is the ratio of the augmentation pressure (due to the reflected component of the pulse pressure wave) to pulse pressure, expressed as a percentage. A decrease in AIx75 and an increase in time to reflection indicate improvements in arterial stiffness. ${ }^{25}$ Central blood pressure and arterial stiffness were measured at baseline before CPAP therapy and follow-up was done after 12 weeks of standard CPAP intervention.

Ethical consideration: This study was approved by Ethics Committee of Faculty of Medicine, Zagazig University, Egypt. A written consent from every patient to participate in the study was obtained. Consistence with ethical standards. Conflict of interest: The authors announce that they have no conflict of interest.

Statistic analyses: The data analysis was performed using the SPSS Statistics 21.0 (IBM, New York, NY, USA) software. The mean \pm standard deviation was used for analysis of quantitive data. A paired $\mathrm{T}$ test was used for comparison between the parameters before and after CPAP that showed changes during treatment. P value $<0.05$ was considered to be statistically significant.

\section{Results}

\section{(Table I)}

As regards the demographic data: there were no statically significant differences between two groups as regards age, gender, body mass index (BMI) and Epworth sleepiness scale (ESS) denoting matching of the studied patients.

\section{Table 2}

In group I: The effective CPAP treatment after 12weeks showed a statistical significant differences between brachial systolic BP before CPAP $(141.6 \pm 2.1)$ after $(140.6 \pm 1.5)(P<0.000)$ and diastolic BP before CPAP $(85.3 \pm 8.2)$ after $(80.9 \pm 7.5)(P<0.000)$.

In group II: The effective CPAP treatment after 12 weeks showed a statistical significant differences between brachial systolic BP before CPAP $(166.4 \pm 3.2)$ after $(135.4 \pm 0.5)(P<0.000)$ and diastolic BP before CPAP $(96.7 \pm 4.5)$ after $(86.8 \pm 2.3)(P<0.000)$.

\section{Table 3}

In group I: The effective CPAP treatment after 12 weeks showed a statistical significant differences between central systolic BP before CPAP $(129.6 \pm 1.8)$ after $(124.2 \pm 0.4)(P<0.000)$ and diastolic BP before CPAP $(86.8 \pm 2.3)$ after $(82.6 \pm 1.5)(P<0.000)$.

In group II: The effective CPAP treatment after 12 weeks showed a statistical significant differences between central systolic BP before CPAP $(155.7 \pm 3.7)$ after $(126.4 \pm 1.2)(P<0.000)$ and diastolic BP before CPAP $(97.3 \pm 2.8)$ after $(85.6 \pm 1.9)(P<0.000)$.

\section{Table 4}

In group I: The effective CPAP treatment after 12 weeks showed a statistical significant differences between pulsed wave velocity before CPAP $(12.6 \pm 2.5)$ after $(10.9 \pm 1.3)(P<0.001)$ and augmentation index before CPAP $(21.6 \pm 11.0)$ after $(18.7 \pm 9.3)(P<0.05)$.

In group II: The effective CPAP treatment after 12 weeks showed a statistical significant differences between pulsed wave velocity before CPAP $(13.9 \pm 2.8)$ after $(12.1 \pm 1.6)(P<0.003)$ and augmentation index before CPAP $(24.8 \pm 11.9)$ after $(21.7 \pm 10.1)(P<0.05)$. The effective CPAP treatment after 12 weeks showed significant $B P$ reduction, in central systolic BP $(6.2 \pm 1.6 \mathrm{mmHg}, P<0.005)$, diastolic BP $(4.4 \pm$ $0.7 \mathrm{mmHg}, P<0.001)$ and, brachial systolic $\mathrm{BP}(5.4 \pm 1.4 \mathrm{mmHg}, P<$ $0.03)$ and diastolic $\mathrm{BP}(4.2 \pm 0.8 \mathrm{mmHg}, P<0.05)$. and achieved PWV reduction by $1.7 \pm 1.2 \mathrm{~m} / \mathrm{sec}(P<0.005)$ and a significant reduction in augmentation index (the augmentation index was $24.8 \% \pm 11.9 \%$ ) and the significant reduction in augmentation index up to $6.1 \%(P<0.05)$. 
Table I Demographic data of the study groups

\begin{tabular}{|c|c|c|c|c|c|}
\hline \multirow[t]{2}{*}{ Age ( years) } & $\begin{array}{l}\text { All Patients at } \\
\text { Baseline }(n=60) \\
\text { Mean } \pm \text { SD }\end{array}$ & $\begin{array}{l}\text { All Patients at I2 } \\
\text { Weeks Follow Up } \\
(n=60) \text { Mean } \pm \text { SD }\end{array}$ & $\begin{array}{l}\text { Group I } \\
\text { AHI (I 5-30) } \\
(n=30)\end{array}$ & $\begin{array}{l}\text { Group II } \\
\text { AHI }(>30) \\
(n=30)\end{array}$ & P-value \\
\hline & $63.3 \pm 11.5$ & $63.3 \pm 11.5$ & $61.8 \pm 13.1$ & $62.4 \pm 11.7$ & NS \\
\hline \multicolumn{6}{|l|}{ Gender } \\
\hline -male & $42(70 \%)$ & 42 (70\%) & $22(73.33 \%)$ & $20(66.6 \%)$ & NS \\
\hline -Female & 18 (30\%) & $18(30 \%)$ & $8(26.66 \%)$ & $10(33.4 \%)$ & \\
\hline BMI $(\mathrm{Kg} / \mathrm{m} 2)$ & $30.7 \pm 5.5$ & $30.6 \pm 6.5$ & $30.4 \pm 5.5$ & $32.9 \pm 6.5$ & NS \\
\hline ESS & $10.2 \pm 5.5$ & $7.2 \pm 5.4$ & $9.2 \pm 4.5$ & $13.9 \pm 4.6$ & $<0.05$ \\
\hline
\end{tabular}

BMI: Body Mass Index; ESS: Epworth Sleepiness Scale

Table 2 Brachial blood pressure measurements before and 3 months after CPAP treatment

\begin{tabular}{lllll}
\hline & \multicolumn{2}{l}{ Group I (N=30) } & Mean \pm SD & \multicolumn{2}{l}{ Group II (N=30) Mean \pm SD } \\
\hline & Before CPAP & After CPAP & $\begin{array}{l}\text { Before } \\
\text { CPAP }\end{array}$ & After CPAP \\
\hline SBP $(\mathrm{mmHg})$ & $141.6 \pm 2 . I$ & $135.4 \pm 0.5$ & $166.4 \pm 3.2$ & $140.6 \pm 1.5$ \\
P value & $<0.000$ & & $<0.000$ & \\
DBP $(\mathrm{mmHg})$ & $85.3 \pm 8.2$ & $80.9 \pm 7.5$ & $96.7 \pm 4.5$ & $86.8 \pm 2.3$ \\
P value & $<0.000$ & & $<0.000$ & \\
\hline
\end{tabular}

SBP: Systolic Blood Pressure; DBP: Diastolic Blood Pressure.

Table 3 Central blood pressure measurements before and 3 months after CPAP treatment

\begin{tabular}{lllll}
\hline & \multicolumn{2}{l}{ Group I $(\mathbf{N}=30)$} & Mean \pm SD & \multicolumn{2}{l}{ Group II (N=30) } & Mean \pm SD \\
\hline & Before CPAP & After 3months & Before CPAP & After 3months \\
\hline c SBP $(\mathrm{mmHg})$ & $129.6 \pm \mathrm{I} .8$ & $124.2 \pm 0.4$ & $155.7 \pm 3.7$ & $126.4 \pm 1.2$ \\
P value & 0 & & 0 & \\
CDBP $(\mathrm{mmHg})$ & $86.8 \pm 2.3$ & $82.6 \pm 1.5$ & $97.3 \pm 2.8$ & $85.6 \pm 1.9$ \\
P value & 0 & & 0 & \\
\hline
\end{tabular}

cSBP: Central Systolic Blood Pressure; cDBp: Central Diastolic Blood Pressure.

Table 4 Arterial stiffness measurements before and 3months after CPAP treatments

\begin{tabular}{lllll}
\hline & Group I $(\mathbf{N}=30)$ & Mean \pm SD & \multicolumn{2}{l}{ Group II (N=30) } \\
& Before CPAP & After 3 months & Before CPAP & After 3 months \\
\hline PWV $(\mathrm{m} / \mathrm{sec})$ & $12.6 \pm 2.5$ & $10.9 \pm 1.3$ & $13.9 \pm 2.8$ & $12.1 \pm 1.6$ \\
P value & 0.001 & & 0.003 & \\
Alx75 & $21.6 \pm 11.0$ & $18.7 \pm 9.3$ & $24.8 \pm 11.9$ & $21.7 \pm 10.1$ \\
P value & $<0.05$ & & $<0.05$ & \\
\hline
\end{tabular}

PWV: Pulsed Wave Velocity;Alx75:Alx values were normalized to a Standard Heart Rate of 75 per minutes.

\section{Discussion}

Arterial stiffening is the early signs of arterial remodeling, leading to high central aortic pressures. ${ }^{26-28}$ The association between OSA and arterial stiffness has been suggested by several studies..$^{27,29,30}$ Controlled cross-sectional study has shown that in patients with minimally symptomatic OSA, arterial stiffness is increased, when compared with well matched control subjects without OSA. ${ }^{30}$ Continuous positive airway pressure, as the primary way to treat OSA, is the most efficient therapy for maintaining upper-airway patency during sleep. Studies have shown that CPAP can improve endothelial function, sympathic and vagal balance, and then further improve arterial stiffness. ${ }^{31-33}$ Therefore, it is expected that CPAP therapy could decrease arterial stiffness in OSA patients. Tsioufi et al.,${ }^{34}$ suggested that OSAS has a significant incremental effect on aortic stiffening in the setting of middle-aged essential hypertensive subjects. Thus, OSAS in a hypertensive patient may accelerate vascular damage, increasing cardiovascular risk. In the longitudinal community-based cohort study Kaess et al., ${ }^{35}$ shows that higher aortic stiffness, forward wave amplitude (FWA), and augmentation index were associated with higher risk of incident hypertension. So, vascular stiffness may be a precursor rather than the result of hypertension. In our study we show that CPAP can improve arterial stiffness in patients with OSA and hypertension, and we speculated that it might be beneficial to delay or prevent the occurrence of cardiovascular disease in patients with OSA and hypertension. ${ }^{36}$ As in the study of Kartali, ${ }^{28}$ the PWV is reduced at first night and further decreased after 3 months of treatment compared to baseline which implies that not only a functional, but also a structural change is taking place in the arteries.. It seems that the effect of CPAP on PWV reaches a very high point very early in its use and continuous use maintains the positive outcome, having reached a plateau. In the present study, addition of effective CPAP decreased arterial stiffness to a greater extent. 37 our study population showed high PWV values, which is in agreement with the data reported in the literature. ${ }^{37-39}$ In our study The effective CPAP treatment after 12 weeks showed significant BP reduction, in central systolic BP $(6.2$ $\pm 1.6 \mathrm{mmHg}, \mathrm{P}<0.005)$, diastolic $\mathrm{BP}(4.4 \pm 0.7 \mathrm{mmHg}, \mathrm{P}<0.001)$ and, brachial systolic BP $(5.4 \pm 1.4 \mathrm{mmHg}, \mathrm{P}<0.03)$ and diastolic $\mathrm{BP}(4.2$ $\pm 0.8 \mathrm{mmHg}, \mathrm{P}<0.05)$ and achieved $\mathrm{PWV}$ reduction by $1.7 \pm 1.2 \mathrm{~m} /$ $\sec (\mathrm{P}<0.005)$ and a significant reduction in augmentation index (the augmentation index was $24.8 \% \pm 11.9 \%$ ) and the significant reduction 
in augmentation index up to $6.1 \%(\mathrm{P}<0.05)$. It should be emphasized that, according to the literature, a decrease in PWV of $1.6 \mathrm{~m} / \mathrm{sec}$ is equivalent to functional "rejuvenation" of vessels for 15 years. ${ }^{40,41}$ The initial augmentation index has been reported to be an independent risk factor for cardiovascular disease, and the augmentation index has been reported to be higher in patients with OSA than in controls. ${ }^{42}$ In our study, the effective CPAP treatment achieved a significant improvement in the augmentation index. Several recent studies have reported that aortic pressure is a more precise predictor of target organ damage than conventional brachial $\mathrm{BP} .^{43}$ The central $\mathrm{BP}$ reduction observed in our study is in agreement with the results reported by Phillips et al after 2months of CPAP $(-4.2 \mathrm{~mm} \mathrm{Hg}){ }^{44}$ It should be noted that this relatively minor central BP decrease may be significant in terms of prognosis, given the finding of the ASCOT-CAFÉ study that an intergroup difference of $3.6 \mathrm{mmHg}$ in central $\mathrm{BP}$ decreased cardiovascular mortality by $24 \%$ and the risk of fatal and nonfatal stroke by $23 \%{ }^{42}$ which may explain the benefits in terms of cardiovascular morbidity and mortality. The basis of this "additional" reduction in central BP seems to be related to an impact on arterial stiffness and the reflected wave. In our study, the duration of CPAP treatment was 3 months, but seems to have been adequate to observe the "additional" effect on central BP. This "additional" decrease of central systolic BP was shown after effective CPAP was $(6.2 \pm 1.6 \mathrm{mmHg}, \mathrm{P}<0.005)$. Therefore, our results suggest that the beneficial effect of CPAP in patients with OSA and arterial hypertension is related, at least in part, to an improvement in arterial stiffness and reflected wave parameters and augmentation index reduction. Recent guidelines by the UK National Institute for Health and Clinical Excellence (NICE) and US Preventive Services Task Force (USPSTF) suggest that the diagnosis of clinic hypertension be confirmed using ABPM in efforts to avoid misdiagnosis and overtreatment. ${ }^{45,46}$ There are several validated devices available, which estimate cSBP using oscillometric upperarm cuff-based methods: a Mobil-OGraph NG (IEM) uses ARCSolver algorithm to compute the cSBP, and the pressure waveform is obtained at the diastolic level. The Tel-O-GRAPH uses exactly the same mathematic algorithm for calculation of the CSBP (ARCSolver) as Mobil-O-GRAPH does. Until now, the measurements of cSBP with tonometry have been limited to clinical studies, because measurement performance required additional trained personnel, additional time, additional technical equipment and certain positions of the patients. The results of our study confirm the validity of the oscillometric measurement of cSBP using the inbuilt ARCSolver algorithm, as reported by several previous studies. These studies used a validated method with a new device. ${ }^{47-49}$

\section{Conclusion}

The effective CPAP therapy in hypertensive patients with OSA reduces both central aortic and peripheral blood pressure and improvements in arterial stiffness parameters. The effective reduction of augmentation index and arterial stiffness will prevent cardiovascular morbidity and mortality.

\section{Limitations}

A single-center study and its relatively small sample size and short duration further studies in a larger number of patients are needed. The main limitation of the study is that the validation was not performed against invasive measurement of cSBP, which was not done because of the obvious risk of invasive procedure. We are also aware that the brachial BP, which was used to compute the cSBP, can vary. Thus, the true brachial BP during the measurement with the Sphygmocor could have been changed compared with the used brachial BP value measured previously with the mobil-o-graph $24 \mathrm{~h}$
PWA monitor, although the time delay between the measurements was as short as possible. Dependent on the subject's constitution, and thus contributing to a certain variation of the computed values, as well as certain population selection bias.

\section{Acknowledgements}

None.

\section{Conflicts of interest}

Author declares there are no conflicts of interest.

\section{Funding}

None.

\section{References}

1. White DP. Sleep-related breathing disorder. Pathophysiology of obstructive sleep apnoea. Thorax. 1995;50(7):797-804.

2. Young T, Peppard PE, Gottlieb DJ. Epidemiology of obstructive sleep apnea: a population health perspective. Am J Respir Crit Care Med. 2002;165(9):1217-1239.

3. Young T, Palta M, Dempsey J, et al. The occurrence of sleepdisordered breathing among middle-aged adults. $N$ Engl J Med. 1993;328(17):1230-1235.

4. Heinzer R, Vat S, Marques-Vidal P, et al. Prevalence of sleepdisordered breathing in the general population: the HypnoLaus study. Lancet Respir Med. 2015;3(4):310-318.

5. Partinen M, Guilleminault C. Daytime sleepiness and vascular morbidity at seven-year follow-up in obstructive sleep apnea patients. Chest. 1990;97(1):27-32.

6. Millman RP, Redline S, Carlisle CC, et al. Daytime hypertension in obstructive sleep apnea. Prevalence and contributing risk factors. Chest. 1991;99(4):861-866.

7. Baguet JP, Hammer L, Levy P, et al. Night-time and diastolic hypertension are common and underestimated conditions in newly diagnosed apnoeic patients. J Hypertens. 2005;23(3):521-527.

8. Young T, Peppard PE, Gottlieb DJ. Epidemiology of obstructive sleep apnea: a population health perspective. Am J Respir Crit Care Med . 2002;165(9):1217-1239.

9. Kohler M, Stradling JR. Mechanisms of vascular damage in obstructive sleep apnea. Nat Rev Cardiol. 2010;7(12):677-685.

10. Laurent S, Boutouyrie P, Asmar R, et al. Aortic stiffness is an independent predictor of all-cause and cardiovascular mortality in hypertensive patients. Hypertension . 2001;37(5):1236-1241.

11. Doonan RJ, Scheffler P, Lalli M, et al. Increased arterial stiffness in obstructive sleep apnea: a systematic review. Hypertens Res. 2011;34(1):23-32.

12. Vlachantoni, Dikaiakou E, Antonopoulos CN, et al. Effects of continuous positive airway pressure (CPAP) treatment for obstructive sleep apnea in arterial stiffness: a meta-analysis. Sleep Med Rev. 2013;17(1):19-28.

13. Doris Moser, Peter Anderer, Georg Gruber, et al. Sleep Classification According to AASM and Rechtschaffen \& Kales: Effects on Sleep Scoring Parameters. Sleep. 2009; 32(2):139-149.

14. Punjabi NM, Newman AB, Young TB, et al. Sleep-disordered breathing and cardiovascular disease: an outcome-based definition of hypopneas. Am J Respir Crit Care Med. 2008;177(10):1150-1155.

15. Barbe F, Durán Cantolla J, Capote F, et al. Long-term effect of continuous positive airway pressure in hypertensive patients with sleep apnea. Am J Respir Crit Care Med . 2010;181(7):718-726. 
16. Dursunoğlu D, Dursunoğlu N. Heart failure and sleep apnea. Turk Kardiyol Dern Arş. 2010;38:135-143.

17. Fleetham J, Ayas N, Bradley D, et al. Canadian Thoracic Society guidelines: diagnosis and treatment of sleep disordered breathing in adults. Can Respir J . 2006;13(7): 387-392.

18. American Academy of Sleep Medicine. International classification of sleepdisorders. (2nd edn), Diagnostic and coding manual. 2005. p. 298.

19. German Society of Sleep Research and Sleep medicine (DGSM) S3 guidelines on non restorative sleep/sleep disorders. Somnologie. 2009;13:1-160

20. Mancia G, Laurent S, Agabiti-Rosei E. Reappraisal of European guidelines on hypertension management: a European Society of Hypertension Task Force document. Blood Pressure. 2009;18(6):308-347.

21. Mancia G, De Backer G, Dominiczak A, et al. 2007 Guidelines for the management of arterial hypertension. The Task Force for the Management of Arterial Hypertension of the European Society of Hypertension (ESH) and of the European Society of Cardiology (ESC). Eur Heart J. 2007;25(6):1462-1536.

22. Vlachantoni IT, Dikaiakou E, Antonopoulos CN, et al. Effects of continuous positive airway pressure (CPAP) treatment for obstructive sleep apnea in arterial stiffness: a meta-analysis. Sleep Med Rev. 2013;17(1):19-28

23. The Report of an American Academy of Sleep Medicine Task Force. Sleep-related breathing disorders in adults: recommendations for syndrome definition and measurement techniques in clinical research. Sleep. 1999;22(5):667-689.

24. Van Bortel LM, Laurent S, Boutouyrie P, et al. Artery Society; European Society of Hypertension Working Group on Vascular Structure and Function; European Network for Noninvasive Investigation of Large Arteries. Expert consensus document on the measurement of aortic stiffness in daily practice using carotid-femoral pulse wave velocity. $J$ Hypertens. 2012;30(3):445-448.

25. Wassertheurer S, Kropf J, Weber T, et al. A new oscillometric method for pulse wave analysis: comparison with a common tonometric method. $J$ Hum Hypertens. 2010; 24(8):498-504.

26. Laurent S, Boutouyrie P, Asmar R, et al. Aortic stiffness is an independen predictor of all-cause and cardiovascular mortality in hypertensive patients. Hypertension . 2001;37(5):1236-1241.

27. Doonan RJ, Scheffler P, Lalli $\mathrm{M}$, et al. Increased arterial stiffness in obstructive sleep apnea: a systematic review. Hypertens Res. 2011;34(1):23-32.

28. Vlachopoulos C,Aznaouridis K, Stefanadis C. Prediction of cardiovascular events and all-cause mortality with arterial stiffness: a systematic review and meta-analysis. J Am Coll Cardiol. 2010;55(13):1318-1327.

29. Korcarz CE, Gepner AD, Peppard PE, et al. The effects of sleepdisordered breathing on arterial stiffness are modulated by age. Sleep 2010;33(8):1081-1085.

30. Kohler M, Craig S, Nicoll D, et al. Endothelial function and arterial stiffness in minimally symptomatic obstructive sleep apnea. Am J Respir Crit Care Med. 2008;178(9):984-988.

31. Vlachantoni IT, Dikaiakou E, Antonopoulos CN, et al. Effects of continuous positive airway pressure (CPAP) treatment for obstructive sleep apnea in arterial stiffness: a meta-analysis. Sleep Med Rev. 2013;17(1):19-28.

32. Shiina K, Tomiyama H, Takata Y, et al. Effects of CPAP therapy on the sympathovagal balance and arterial stiffness in obstructive sleep apnea. Respir Med. 2010;104(6):911-916.
33. Kohler M, Craig S, Pepperell JC, et al. CPAP improves endothelial function in patients with minimally symptomatic OSA: results from a subset study of the MOSAIC trial. Chest. 2013;144(3):896-902.

34. Tsioufis C, Thomopoulos K, Dimitriadis K, et al. The incremental effect of obstructive sleep apnoea syndrome on arterial stiffness in newly diagnosed essential hypertensive subjects. J Hypertens. 2007;25(1):141-146.

35. Kaess BM, Rong J, Larson MG, et al. Aortic stiffness, blood pressure progression, and incident hypertension. JAMA. 2012;308(9):875-881.

36. Xin Lin, Gongping Chen, Jiachao Qi, et al. Effect of continuous positive airway pressure on arterial stiffness in patients with obstructive sleep apnea and hypertension: a meta-analysis. Eur Arch Otorhinolaryngol. 2016;273(12):4081-4088.

37. Nagahama H, Soejima M, Uenomachi H. Pulse wave velocity as an indicator of atherosclerosis in obstructive sleep apnea syndrome patients. Intern Med. 2004;43(3):184-188.

38. Drager LF, Bortolotto LA, Figueiredo AC, et al. Obstructive sleep apnea, hypertension and their interaction on arterial stiffness and heart remodeling. Chest. 2007;13(5):1379-1386.

39. Parati G, Lombardi C, Hedner J, et al. Position paper on the management of patients with obstructive sleep apnea and hypertension: join recommendations by the European Society of Hypertension, by the European Respiratory Society and by the members of European COST (COoperation in Scientific and Technological research) ACTION B26 on obstructive sleep apnea. J Hypertens. 2012;30(4):633-646.

40. Mäki-Petäjä KM, Booth AD, Hall FC, et al. Ezetimibe and simvastatin reduce inflammation, disease activity, and aortic stiffness and improve endothelial function in rheumatoid arthritis. $J \mathrm{Am}$ Coll Cardiol. 2007;50(9):852-858.

41. Nichols WW, O'Rourke MF. McDonald's Blood Flow in Arteries: Theoretical, Experimental and Clinical Principles. (5th edn), Hodder Arnold, London, UK. 2005.

42. Kohler M, Craig S, Nicoll D, et al. Endothelial function and arterial stiffness in minimally symptomatic obstructive sleep apnea. Am J Respir Crit Care Med. 2008;178(9):984-988

43. Williams B, Lacy PS, Thom SM, et al. Differential impact of blood pressure-lowering drugs on central aortic pressure and clinical outcomes: principal results of the CAFE study. Circulation. 2006;113(9):1213-1225.

44. Phillips CL, Yee B, Yang Q, et al. Effects of continuous positive airway pressure treatment and withdrawal in patients with obstructive sleep apnea on arterial stiffness and central BP. Chest. 2008;134(1):94-100.

45. National Clinical Guideline Centre. Hypertension: The Clinical Management of Primary Hypertension in Adults: Update of Clinical Guidelines 18 and 34 [Internet]. NICE Clinical Guidelines, No. 127. Royal College of Physicians: London, UK. 2011.

46. Siu AL. Screening for high blood pressure in adults: U.S. Preventive Services Task Force recommendation statement. Ann Intern Med. 2015;163(10):778-786.

47. Wassertheurer S, Kropf J, Weber T, et al. A new oscillometric method for pulse wave analysis: comparison with a common tonometric method. $J$ Hum Hypertens. 2010;24(8):498-504.

48. Weber T, Wassertheurer S, Rammer M, et al. Validation of a brachia cuff-based method for estimating central systolic blood pressure. Hypertension. 2011;58(5):825-832.

49. Weiss W, Gohlisch C, Harsch-Gladisch C, et al. Oscillometric estimation of central blood pressure: validation of the Mobil-O-Graph in comparison with the SphygmoCor device. Blood Press Monit. 2012;17(3):128-131. 